\title{
Organofosforlu Pestisidlerden Phosmet'in Pseudomonas fluorescens ile Biyodegradasyonunun Dolgulu Kolon Reaktörde Araştırılması
}

\author{
Organophosphorus Pesticides Phosmet's Investigation of Biodegradation with \\ Pseudomonas fluorescens in Filled Column Reactor
}

\author{
Gülşad USLU ŞENEL* ${ }^{* 1, a}$, Selin YILMAZ DURDU ${ }^{2, b}$ \\ ${ }^{I}$ Fırat Üniversitesi, Mühendislik Fakültesi, Çevre Mühendisliği Bölümü, 23100, Elazı ̆̆

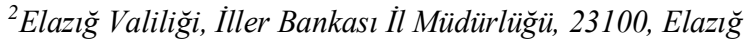

• Geliş tarihi / Received: 25.01.2020 • Düzeltilerek geliş tarihi / Received in revised form: 28.02.2020 • Kabul tarihi / Accepted: 03.03.2020

Öz

Bu çalışmada $\mathrm{dp}=2 \mathrm{~mm}$ çaplı tutuklanmış $P$. fluorescences tanecikleri ile dolgulu kolon reaktörde, öncelikle $1 \mathrm{mg} / \mathrm{L}$ phosmet derişiminde besleme akış hızının phosmet tüketim hızına etkisi incelenmiştir. Akış hızı arttıkça filmm difüzyon direncinin azaldığı ve phosmet tüketim hızının arttı̆̆g gözlenmiştir. En yüksek phosmet \% tüketim değeri (\% 99) en düşük akış hızında $(1.17 \mathrm{~mL} /$ dak$)$ elde edilmiştir. Amaç yüksek dönüşüm yüzdesi elde etmek olduğu kadar, yüksek phosmet tüketim hızıda sağlamak olduğundan $1.67 \mathrm{~mL} / \mathrm{dak}$ akış hızı daha sonraki denemelerde kullanılabilecek akış hızı olarak belirlenmiştir. Bu akış hızında elde edilen phosmet tüketim hızı; $0.0096 \mathrm{mg} / \mathrm{g}$ k.mo.sa, tüketim yüzdesi ise \% 97.5'dur. Dolgulu kolon reaktörde phosmet giderimi \%99 olarak belirlenmiştir. Analizler tarımsal üretiminde yaygın olarak kullanılan phosmetin çevreye olumsuz etkilerini azaltmak için alternatif olarak dolgulu kolon reaktörde bakteriyel biyokütlenin kullanılabileceğini göstermiştir.

Anahtar kelimeler: Dolgulu Kolon Reaktör, Phosmet, Pseudomonas Fluorescens

\begin{abstract}
In this study, the effect of feed flow rate on phosmet consumption rate was investigated at a concentration of $1 \mathrm{mg} / \mathrm{L}$ phosmet in a column reactor filled with arrested $P$. fluorescences particles with $d p=2$ mm diameter. It was observed that the film diffusion resistance decreased and phosmet consumption rate increased with increasing flow rate. The highest phosmet \% consumption value (99\%) was obtained at the lowest flow rate $(1.17 \mathrm{~mL} / \mathrm{min})$. Since the goal was to achieve a high conversion percentage as well as a high phosmet consumption rate, a flow rate of $1.67 \mathrm{~mL} / \mathrm{min}$ was determined as the flow rate that could be used in subsequent trials. The phosmet consumption rate obtained at this flow rate; $0.0096 \mathrm{mg} / \mathrm{g}$ k.mo.sa, the percentage of consumption is $97.5 \%$. Phosmet removal in the filled column reactor was determined as 99\%. Experiments have shown that fungal biomass can be used as an alternative to reduce the negative environmental impacts of phosmet, which is widely used in agricultural production.
\end{abstract}

Keywords: Continuous Reactor, Phosmet, Pseudomonas Fluorescences

*a Gülşad USLU ŞENEL; guslu @ firat.edu.tr., Tel: (0533) 7483553, orcid.org/0000-0002-5304-9436

${ }^{\mathrm{b}}$ orcid.org/0000-0002-0000-0000 


\section{Giriş}

Dünya nüfusunun artmasıyla birlikte ortaya çıkan gida maddesi ihtiyacı tarımsal üretimden maksimum verim elde edebilmek için gübre ve pestisit kullanımını zorunlu hale getirmiştir (Storck vd., 2017; Chen vd., 2017). Hem Türkiye'de hem de dünyada tarımı destek amaciyla kullanılan pestisitler sayesinde, yeterli miktarda ve kalitede ürün elde edilmektedir (Hillocks, 2012).

Dünya genelinde ve ülkemizde olduğu gibi pestisit kullanımı her geçen gün artmakta ve ekolojik döngüyü bozmaktadır. Günlük yaşantımızda her alanda rastlayabileceğimiz pestisitler özellikle tarımsal faaliyetlerde yoğun olarak kullanılmakta ve çevresel taşınımları sonucunda su kaynaklarına ulaşabilmektedir. Artan popülasyon neticesinde tarım alanlarından daha fazla ürün alma isteği bu bölgelerde uygulanan zirai ilaç kullanımını da arttırmaktadır. Bilinçsiz ve düzensiz aşırı ilaç kullanımı topraktan süzülerek yüzeysel sulara ve yeraltı su kaynaklarına ulaşmaktadır. Kullanılan bu ilaçlar pestisit olarak bilinen oldukça toksik, biyolojik olarak kararlı ve aynı zamanda çok düşük konsantrasyonlarda bulunan kimyasallardır. Pestisitlerin ihtiyaç duyulan dozlardan fazla kullanımı, alıcı ortamın doğal dengesini bozarken aynı zamanda insan sağlı̆̆ etkilere yol açtı̆̆ 1 bilinmektedir.

Uzun süre bozunmadan doğada kalan pestisitler konvansiyonel arıtım yöntemleri ile yeterince arttılamamaktadır (Jasim vd., 2006; Curutio vd., 2017). Çeşitli sebeplerle doğal su kaynaklarına, yeraltı suyuna ve toprağa ulaşan pestisitler ve parçalanma ürünleri canlılara zarar vermektedir. Pestisitle kirlenmiş suların kullanılması insanlar ve diğer canlılar için tehlike oluşturmaktadır (Pazı vd., 2013; Ardıç, 2013). Alıcı ortamlarda pestisitlerin tespiti sonucunda bu kirleticilerin; fizikokimyasal arıtma, koagülasyon flokülasyon, adsorpsiyon, biyolojik arıtma, ileri oksidasyon prosesleri, membran prosesleri ve hibrit prosesler gibi birçok değişik arıtma teknikleri pestisit gideriminde kullanılmaktadır (Kitiş, 2014).

Pestisitlerin toksik ve kompleks yapılarından dolayı sulardan biyolojik olarak giderimi oldukça sınırlıdır (Feakin vd., 1995). Genel olarak bir pestisitin biyolojik parçalanması, üç ana kategoride incelenmektedir. Birinci kategoride parçalanma az veya yok gibidir. $\mathrm{Bu}$ durumda pestisit molekülü aktivitesini uzunca bir süre toprakta sürdürebilir. Çevre kirliliği açısından en zehirli olan kategori budur. İkinci kategorideki pestisit molekülü, toprak ve su kaynaklarının kirlenmesine neden olmayacak şekilde yavaş bir ayrışmaya uğramaktadır. Üçüncüde ise, pestisit molekülünü sadece kısmi bir bozunmaya uğramakta ve bu nedenle da bu tipteki pestisitler çevrede en çok birikim eğilimi gösteren bileşikler olarak görülmektedir. Pestisit kalıntılarının biyolojik bozunmalarında yer alan mikroorganizma tür ve cinsleri çok çeşitlidir. Pestisitlerin biyolojik mineralizasyon süreçlerinde en etkin olan bakteri cinsleri Pseudomonas, Agrebacterium, Bacillus ve Achromobacter'dir. Pestisitlerin biyodegradasyonu etkileyen faktörler sirasiyla sicaklık, bekleme süresi, nütrient muhtevası, çözünmüş oksijen konsantrasyonu, mikrobiyal popülasyon ve pestisitin çözünürlüğ̈̈dür (Fernandes vd., 2013; Antonious, 2012; Chowdhury vd., 2008).

Dünyada yapılan birçok çalışma kirleticilerinin tanımlanması ve teşhisi üzerinedir. Son yıllarda yapılan çalışmalar ise çeşitli pestisitlerle kirlenmiş alıcı ortamların bu kirleticilerden giderilmesinde görev alan mikroorganizmaları tanımlamaya yönelik olmuştur. Biyodegradasyon, mikroorganizmalar tarafindan kısa sürede gerçekleştiği için önemli bir arıtım tekniğidir. Özellikle bakteriler hem doğal veya yapay kirleticilere karşı dirençli olmaları hem de sentezledikleri enzimler sayesinde biyolojik bozunmayı destekledikleri için ilgi odağı haline gelmiştir. Bununla birlikte, bazı funguslar, algler, arkeler ve bitkiler de pestisitleri biyolojik olarak parçalayabilme özelliğine sahiplerdir (Copley, 2009). Literatürde bakteriler tarafindan pestisitlerin özellikle de herbisitlerin biyodegradasyonu ile ilgi yapılan birçok çalışma vardır (Radosevich vd., 1995; Struthers vd., 1998; Bending vd., 2003). Ancak Phosmet pestisitinin giderimi konusunda yapılan çalışmalar çok sinırlıdır. Kullanımı oldukça yaygın olan ve özellikle sucul çevresel ortamlara giriş yapmış olan phosmetin giderimiyle ilgili farkl 1 giderim yöntemlerinin detaylı olarak araştırılması gerekmektedir. Phosmetin biyodegradasyon kapasitesini belirlemek ve arıtma formülasyonları geliştirmek bu kirleticilerle kirlenmiş atıksuların yönetiminde önemlidir. $\mathrm{Bu}$ çalışmanın amacı, phosmetin biyodegradasyon yöntemleriyle dolgulu kolon reaktörde giderim etkinliğini araştırmaktır. $\mathrm{Bu}$ amaçla $\mathrm{dp}=2 \mathrm{~mm}$ çaplı tutuklanmış $P$. fluorescences tanecikleri ile dolgulu kolon reaktörde, öncelikle $1 \mathrm{mg} / \mathrm{L}$ phosmet derişiminde besleme akış hızının phosmet tüketim hızına etkisi incelenmiştir. 


\subsection{Dolgulu Kolon Reaktör}

Biyoteknolojik işlemlerde kesikli düzende çalışan reaktörlerin yanında sürekli düzende çalışan kolon tipi reaktörlerin kullanımı da oldukça yaygındır. Dolgulu kolon reaktörler, mikroorganizma miktarı ayarlanarak büyük miktarda atıksu arıtımı yapılabilmesi, mikroorganizma bulaşmasının görülmemesi ve arıtılmış atıksuyun sistemden kolaylıkla ayrılabilmesi gibi özelliklerinden ötürü tercih edilen bir reaktör türüdür. Bu çalışmada phosmetin biyodegradasyonu için kalsiyum aljinatta tutuklanmış $P$. fluorescens taneciklerini içeren dolgulu kolon reaktör kullanılmıştır.

Dolgulu kolon reaktörde phosmet tüketim hızı Denklem (1)'de tüketim yüzdesi ise Denklem (2)'de tanımlanmıştır.

$\boldsymbol{v}_{\mathrm{k}}=\left(\mathrm{C}_{\mathrm{po}}-\mathrm{C}\right) \frac{\mathrm{Q}}{\mathrm{w}}\left(\frac{60}{1000}\right)$

Burada; $\boldsymbol{v}_{\mathrm{k}}$ : Kolon phosmet tüketim hızı (mg phosmet/g k.mo.sa); $\mathrm{C}_{\mathrm{po}}$ : Kolon phosmet besleme derişimi (mg/L); C: Kolon phosmet çıkış derişimi (mg / L); Q: Hacimsel akış hızı (mL / dak); w: Kolondaki toplam kuru mikroorganizma miktarını (g) vermektedir.

$\%$ Tüketim $=\frac{C_{O}-C}{C_{O}} \times 100$

Kolon kesit alanı $\left(\mathrm{cm}^{2}\right)$ A'nın hesabı Denklem (3)' e göre yapılmıştır.

$A=\frac{\pi D^{2}}{4} \varepsilon$

Burada; D: Kolon çapı $(\mathrm{cm}) ; \boldsymbol{\varepsilon}$ : Poroziteyi ifade etmektedir.

Alıkonma süresi ise Denklem (4) yardımıyla hesaplanmıştır.

$\tau=\frac{V}{Q} \varepsilon$

Burada V Boşluk hacmi $\left(\mathrm{cm}^{3}\right)$ 'ni ifade etmektedir.

Dolgulu Kolonda Görünür Tepkime Hız Sabitinin Hesaplanmasl

Dolgulu kolonda substrat için süreklilik denkliği aşağıdaki şekilde verilir.

$\frac{\partial C}{\partial t}=\mathrm{D}_{\mathrm{Z}} \frac{\partial^{2} C}{\partial_{Z^{2}}}+D_{r} \frac{1}{r} \frac{\partial}{\partial_{r}}\left(r \frac{\partial \mathrm{C}}{\partial r}\right)-\mathrm{U} \frac{\partial \mathrm{C}}{\partial \mathrm{z}}-\mathrm{vk}(5)$

-Yatışkın durum, -Tıpa tipi akış, -Radyal ve eksenel yöndeki difüzyonla kütle aktarımı ihmal edilebilir, varsayımları yapılarak Denklem (6) elde edilir.

$U \frac{\partial \mathrm{C}}{\partial \mathrm{z}}=-v_{k}$

Buradaki tepkime hızl $\left(v_{\mathrm{k}}\right) \quad(\mathrm{g} \quad \mathrm{mol} / \mathrm{L}-\mathrm{sa})$ birimindedir. İncelenen tepkime tutuklanmış mikroorganizma ile katalizlenen tepkime olduğundan tepkime hızı (mg/g k.mo.sa) biriminde olmalıdır. Eşitliğin sol tarafi $\mathrm{h} / \mathrm{w}$ ile çarpıldığında ve akış hızı hacimsel akış hızı olarak alındığında gerekli birim değişikliği yapılmış olur.

$\frac{h}{w} Q \frac{\partial C}{\partial z}=-v k$

Burada; h, Kolon boyu (cm); w, Tutuklanmış taneciklerdeki toplam kuru mikroorganizma miktarı (g); Q, Hacimsel akış hızı ( $\mathrm{cm}^{3} /$ dak.)'dır.

Düşük substrat derişimlerinde biyodegradasyonun 1. Derece bir tepkime olduğu kabul edilirse;

$v_{\mathrm{k}}=\mathrm{k}_{\mathrm{p}} \mathrm{C}$

$\mathrm{k}_{\mathrm{p}}$ : Görünür tepkime hızı $\left(\mathrm{cm}^{3} / \mathrm{g}\right.$. sa)'dir.

Denklem 7 ve 8'de kullanılırsa

$\frac{h Q}{w} \frac{d C}{d z}=-k_{p} C$

elde edilir. Denklem (6); $\mathrm{z}=0 \mathrm{C}=\mathrm{C}_{\mathrm{po}}$ ve $\mathrm{z}=\mathrm{h} \mathrm{C}=\mathrm{C}$ sınır koşulları ile çözülürse, Denklem (10) elde edilir.

$\ln \frac{\mathrm{C}_{\mathrm{F}_{\mathrm{O}}}}{\mathrm{C}}=\frac{\mathrm{w}}{\mathrm{Q}} \mathrm{k}_{\mathrm{p}}$

\section{Materyal ve Metot}

\subsection{Mikroorganizma Külttürü}

American Type Culture Collection (A.T.C.C.)'dan Liyofilize halde temin edilen $P$. fluorescens $^{\text {BAA-477 }}$ çalışmalarda kullanılmak üzere zenginleştirilmiş besin ortamında labaratuarda üretilmiştir. $P$. fluorescens'in üretiminde kullanılan zengin sıv1 besiyerinin bileşimi $5 \mathrm{~g} / \mathrm{L}$ glukoz, $1 \mathrm{~g} / \mathrm{L}$ maya özütü, $1 \mathrm{~g} / \mathrm{L}$ pepton, $0,5 \mathrm{~g} / \mathrm{L} \mathrm{K}_{2} \mathrm{HPO}_{4}, 0,5 \mathrm{~g} / \mathrm{L}$ $\mathrm{KH}_{2} \mathrm{PO}_{4}, \quad 0,5 \quad \mathrm{~g} / \mathrm{L}\left(\mathrm{NH}_{4}\right)_{2} . \mathrm{SO}_{4}$ ve $0,05 \mathrm{~g} / \mathrm{L}$ $\mathrm{MgSO}_{4} .7 \mathrm{H}_{2} \mathrm{O}$ 'dur. Sterillenerek üretime hazırlanan besiyerine $P$. fluorescens $1 / 10$ oranında aşılanmıştır. Daha sonra $30{ }^{\circ} \mathrm{C}$ sicaklık ve $150 \mathrm{rpm}$ karıştırma hızında çalışan orbital inkübatörde 24 saat süre ile bekletilerek, $P$. fluorescens' in üremesi gerçekleştirilmiştir (Yılmaz, 2012; Uslu Şenel ve Yilmaz Durdu, 2020). 
Phosmet pestisitinin mikroorganizmalarla biyodegradasyonunda mevcut pestisitten $10 \mathrm{ppm}$ konsantrasyonunda stok çözelti hazırlanmıştır. Besi ortamına bu stok çözeltiden istenilen konsantrasyonu oluşturacak şekilde pipet yardımıyla pestisit çözeltisi ilave edilmiştir.

\subsection{Pestisit Solüsyonu Hazırlanmast ve LC MS/MS Cihazında Tayin Şartlarının Belirlenmesi}

$\mathrm{Bu}$ çalışmada kullanılan phosmet pestisitinin analitik standart1 Dr Ehrenstorfer firmasının Türkiye temsilcisinden temin edilmiş olup $\% 98.5$ saflıktadır. Phosmet pestisitinin etkin maddesi metanolde (\% 98) çözünerek 10 ppm'lik stok çözeltisi hazırlanmıştır. Hazırlanan stok çözelti çalışma süresince derin dondurucuda $-15^{\circ} \mathrm{C}$ 'de muhafaza edilmiştir. Pestisitin stok çözeltisinden seyreltme ile 1- $10 \mathrm{ppm}$ arasinda bir dizi standart çözelti hazırlanmıştır.

LC-MS/MS tekniğinde yüksek basınçlı sıv1 kromatografisinde fizikokimyasal özelliklerine göre ayrılan moleküller kütle dedektörü ile analiz edilmektedir. Birinci kuadrupol filtrede $\mathrm{m} / \mathrm{z}$ (kütle/yük) oranına göre ayrılan moleküller collision gaz adı verilen yüksek saflıkta özel bir gaz ile parçalanmaya tabi tutulmaktadır. İkinci kuadrupol filtrede parçalanma sonucu oluşan iyonların üzerinden teşhis ve miktar tayini yapılmaktadır. Aynı m/z oranına sahip pek çok molekülün mevcut olmasına karşın aynı parçalanma iyonlarına sahip molekül sayısı doğada 1/10000 dür. Bu nedenle LC-MS/MS tekniği çok düşük konsantrasyonlarda maddenin miktar tayininin yapılabilmesini mümkün k1lmaktadır. Ayrıca sonuçların doğrulanmasına da gerek duyulmamaktadır.

LC-MS/MS ile pestisitlerin analizinde öncelikle numuneler vial adı verilen küçük cam şişelere filtreler yardımıyla enjekte edilir. Metanol ve su çözeltisi ile amonyum formattan oluşan hareketli faz belli bir akış hızıyla gelir ve numuneyi alarak sürüklemeye başlar. Kolon kısmına gelir ve buradan da numune MS kısmındaki elektrota geçer. Burada phosmet iyonlaşarak gaz fazına geçer. Buradan gaz 1 'in olduğu kuadropole gelir. $\mathrm{Q}_{0}$ 'da moleküller spiral hareket yaparak sıraya girer. $Q_{1}$ 'de phosmet yakalanır. $\mathrm{Q}_{2}$ 'de azot jeneratöründen gelen azotla phosmet molekülü çarpıştırılır ve parçalanma ürünleri oluşur. $\mathrm{Q}_{3}$ 'de parçalanma ürünleri yakalanarak dedektör tarafindan miktar belirlenir ve pik olarak tayin edilir.
$\mathrm{Bu}$ çalışmada phosmet pestisitinin analizinde Shimadzu marka LC MS/MS cihazı kullanılmıştır.

\subsection{Mikroorganizmantn Tutuklanmast}

$\mathrm{Bu}$ çalışmada kullanılan $P$. fluorescens, iyon değiştirme ile jelleşme temeline göre oluşturulan kalsiyum aljinat jele tutuklanarak kullanılmıştır. İlk olarak bir aljinik asit tuzu olan sodyum aljinattan, $\% 2$ 'lik sodyum aljinat çözeltisi hazırlanmıştır. İkinci olarak; zengin sıvı besi ortamında logaritmik evreye kadar üretilen mikroorganizmalar, 5000 devir/dak. hızda santrifüjlenmiştir. Daha sonra $1 \mathrm{~g}$ yaş hücre/3 mL sodyum aljinat çözeltisi ile karıştırılmıştır. Karışım düzgün küresel tanecikler oluşturabilmek için bir şırınga yardımıyla \% 20’lik kalsiyum klorür çözeltisi içine damlatılmıştır. Sodyum aljinat-mikroorganizma karışımı $\mathrm{CaCl}_{2}$ çözeltisine damlatıldığında kalsiyum iyonları, sodyum iyonları ile yer değiştirir ve kalsiyum aljinat jeli çöker. Böylece mikroorganizma hücreleri de kalsiyum aljinat jeli içine hapis olur. Tutuklanmış hücreleri içeren kalsiyum aljinat taneciklerinin jel oluşumunu tamamlayabilmeleri için en az 2 saat $\mathrm{CaCl}_{2}$ çözeltisi içinde laboratuvar ortamında bekletilmiştir (Yılmaz, 2012).

Çalışmada kullanılan besleme çözeltisi, $15 \mathrm{~L}$ hacminde saf suda $0,005 \mathrm{~g} \quad \mathrm{KH}_{2} \mathrm{PO}_{4}, \quad 0,1 \mathrm{~g}$ $\left(\mathrm{NH}_{4}\right)_{2} \mathrm{SO}_{4}, \quad 0,005 \mathrm{~g} \quad \mathrm{KNO}_{3}, 2 \mathrm{~g} \mathrm{NaCl}, 0,25 \mathrm{~g}$ $\mathrm{MgSO}_{4} .7 \mathrm{H}_{2} \mathrm{O}, \quad 2.25 \mathrm{~g} \quad \mathrm{CaCl}_{3} .2 \mathrm{H}_{2} \mathrm{O}$ bileşikleri çözülerek hazırlanmıştır. Çözeltinin $\mathrm{pH}$ değeri $\mathrm{NaOH}$ ve MOPS çözeltisi ile 8.3'e sabitlenmiştir.

Tutuklanmış mikroorganizmalarla yapılan biyodegradasyon deneylerinde kullanılan siv1 besiyerinin bileşimi, $0,010 \mathrm{~g} / \mathrm{L}$ maya özütü, 0,040g/L pepton, $0,07 \mathrm{~g} / \mathrm{L} \mathrm{KH}_{2} \mathrm{PO}_{4}, 0,015 \mathrm{~g} / \mathrm{L}$ $\left(\mathrm{NH}_{4}\right)_{2} . \mathrm{SO}_{4}$ ve $0,050 \mathrm{~g} / \mathrm{L} \mathrm{MgSO}_{4} .7 \mathrm{H}_{2} \mathrm{O}$ 'dur.

\subsection{Dolgulu Kolon Deney Düzeneği}

Dolgulu kolon reaktör deneylerinde iç çap1 2. 2 . $\mathrm{cm}$, dolgu yüksekliği $27.5 \mathrm{~cm}$ olan pyrex camdan yapılmış bir dolgulu kolon reaktör kullanılmıştır. Kolon ortalama çapı $2 \mathrm{~mm}$ olan tutuklanmış mikroorganizmalarla doldurularak dolgulu yatak elde edilmiştir. Dolgulu Kolon Reaktör sistemi Şekil 1.'de verilmiştir (Y1lmaz, 2012).

\subsection{Mikroorganizma Derişimi Analizi}

Yaş mikroorganizma derişimi $\mathrm{g} / \mathrm{L}$ cinsinden spektrofotometrik olarak tayin edilmiştir. Daha sonra yaş ağırlık-kuru ağırlık çalışma doğrusundan yararlanarak $\mathrm{g} / \mathrm{L}$ cinsinden kuru mikroorganizma derişimine geçilmişsir (Y1lmaz, 2012). 


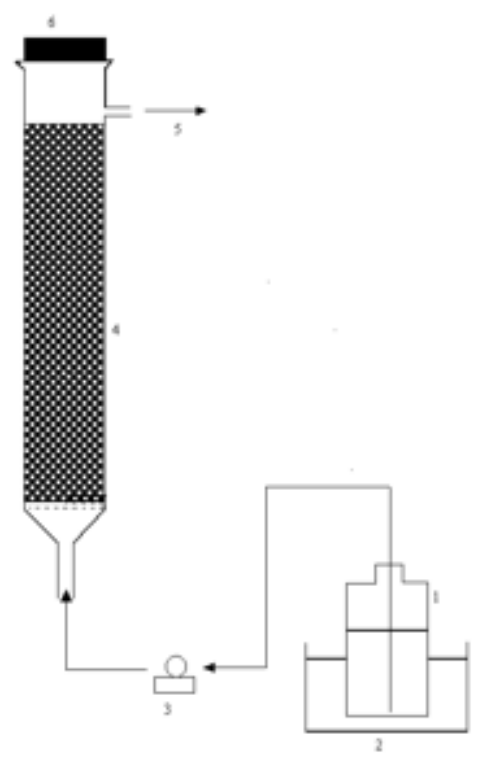

Şekil 1. Dolgulu kolon reaktör akım şeması (1. Besleme çözeltisi tankı; 2. Sabit sıcaklıktaki su banyosu; 3. Besleme pompas1, 4. Dolgulu kolon reaktör; 5.Reaktör çıkışı, 6.Tıpa).

\section{Bulgular}

$\mathrm{Bu}$ çalışmada, besleme akış hızının ve phosmet derişiminin, phosmet tüketim hızına ve verimliliğine etkileri araştırılmıştır.

\subsection{Besleme Akış Hızının Etkisi}

Dolgulu kolon reaktörlerde Besleme akıș hızının phosmet tüketimine etkisi, kolon substrat tüketim hız1 ve substrat tüketim verimi cinsinden araştırılmıştır. $\mathrm{Bu}$ amaçla kalsiyum aljinatta tutuklanmış bakteri hücrelerini içeren ve $30^{\circ} \mathrm{C}$ 'de tutulan dolgulu kolona $\mathrm{pH}$ 7'de $1 \mathrm{mg} / \mathrm{L}$ phosmet içeren ve bileşimi verilen besleme çözeltisi 1.17$4.00 \mathrm{ml} / \mathrm{dak}$. arasında değişen akış hızlarında beslenmiştir. Dolgulu kolonda phosmet tüketim hızının kolon Reynolds Sayısı ile değişimi Şekil 2 'de verilmiştir.

Mikroorganizmalar gözenekli bir matrikste tutuklandığında, substrat ilk olarak tutuklanmış tanecik etrafındaki film tabakasından difüzlenerek porların içine ulaşır. Burada reaksiyon verir ve ürünler sıvı besin ortamına difüzlenir. Düşük akış hızlarında tanecik etrafindaki film tabakası direnci kırılamadığından düşük phosmet tüketim hızları gözlenmektedir. Akış hızı artırıldığında ise phosmet tüketim hızı bir plato değerinde kalmaktadır. Substrat dönüşüm yüzdesi açısından veriler değerlendirildiğinde ise akış hızının artması ile dönüşüm yüzdesinin sürekli olarak azalması söz konusudur (Tablo 1). En yüksek substrat tüketim yüzdesi en düşük akış hızı olan $1.17 \mathrm{~mL} /$ dak'da elde edilmiştir. Düşük alıkonma sürelerinde çalışıldığ 1 takdirde, sistemde geri döngü yapılarak \% dönüşüm artırılabilir. Tek geçişte amaç yüksek dönüşüm verimi elde etmek olduğundan aynı zamanda film direncini düşük, substrat dönüşüm hızını da yüksek seviyede tutabilmek için 1.67 $\mathrm{mL} /$ dak besleme akış hızı, daha sonraki çalışmalarda kullanılabilecek uygun bir değer olarak belirlenmiştir.

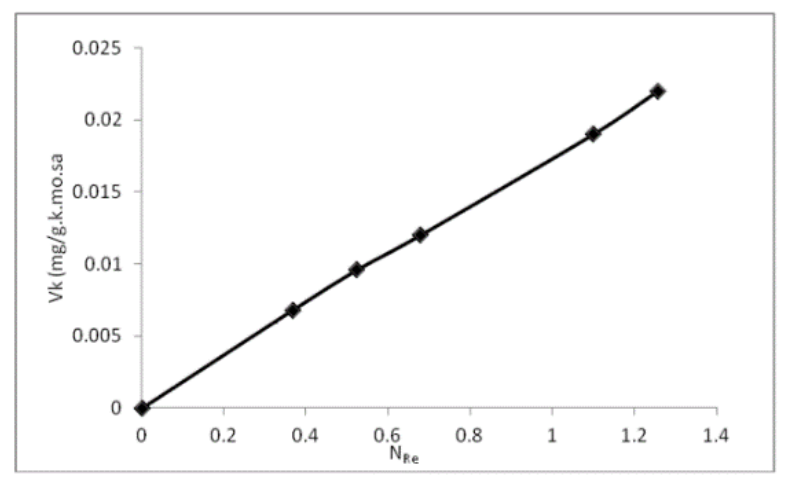

Şekil 2. Dolgulu kolonda phosmet tüketim hızının kolon reynolds sayısı ile değişimi $\left(\mathrm{pH}=7, \mathrm{~T}=30^{\circ} \mathrm{C}\right.$, $\mathrm{C}_{\mathrm{po}}=1 \mathrm{mg} / \mathrm{L}, \mathrm{w}=10.15 \mathrm{~g}, \boldsymbol{\varepsilon}=0.33, \mathrm{dp}=2 \mathrm{~mm}$ )

Tablo 1. Farklı akış hızlarında elde edilen alıkonma süreleri ve $\%$ phosmet tüketim değerleri $\left(\mathrm{pH}=7, \mathrm{~T}=30^{\circ} \mathrm{C}, \mathrm{C}_{\mathrm{po}}=1 \mathrm{mg} / \mathrm{L}, \mathrm{w}=10.15 \mathrm{~g}, \boldsymbol{\varepsilon}=\right.$ $0.33)$

\begin{tabular}{lccc}
$\mathrm{Q}(\mathrm{mL} / \mathrm{dak})$ & $\boldsymbol{\tau}$ (sa) & \% Tüketim & $\mathrm{N}_{\mathrm{Re}}$ \\
\hline & & & \\
1.17 & 0.56 & 99 & 0.367 \\
1.67 & 0.39 & 97.5 & 0.524 \\
2.16 & 0.30 & 96.7 & 0.678 \\
3.5 & 0.19 & 95.6 & 1.099 \\
4.0 & 0.16 & 94.9 & 1.256 \\
\hline
\end{tabular}

\subsection{Besleme Phosmet Derişiminin Etkisi}

Başlangıç phosmet derişiminin kolon phosmet tüketim hızına ve $\%$ dönüşümüne etkisi, $30^{\circ} \mathrm{C}$ sabit sıcaklık, başlangıç pH'1 7 ve $1.67 \mathrm{~mL} /$ dak besleme akış hızında incelenmiş, sonuçlar Şekil 3'de; farklı phosmet derişimlerinde elde edilen kolon phosmet yüzde tüketim değerleri ise Tablo 2'de verilmiştir. Şekil 3 ve Tablo 2'den de görüldüğü gibi phosmet derişimi arttıkça kolon phosmet tüketim hızı artarken, tüketim yüzdesi ise $\% 97.5$ 'den $\% 55.4$ 'e kadar azalmıştır. Dolgulu kolonda amaç yüksek \% dönüşüm sağlamak olduğu kadar yüksek substrat tüketim hızı da elde etmektir. 


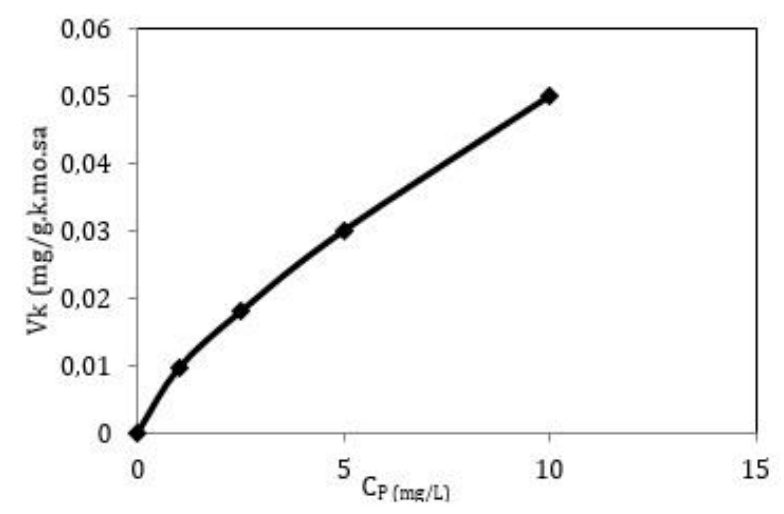

Şekil 3. Phosmet derişiminin kolon phosmet tüketim hızına etkisi $\left(\mathrm{pH}=7, \mathrm{~T}=30^{\circ} \mathrm{C}, \mathrm{C}_{\mathrm{P}_{0}}=1 \mathrm{mg} / \mathrm{L}\right.$, $\mathrm{w}=10.15 \mathrm{~g}, \boldsymbol{\varepsilon}=0.33, \mathrm{dp}=2 \mathrm{~mm}, \boldsymbol{\tau}=0.30 \mathrm{sa})$

Tablo 2. Farklı phosmet derişimlerinde elde edilen kolon $\%$ phosmet tüketim değerleri $(\mathrm{pH}=7$, $\left.\mathrm{T}=30^{\circ} \mathrm{C}, \mathrm{w}=10.15 \mathrm{~g}, \boldsymbol{\varepsilon}=0.33 \boldsymbol{\tau}=0.30 \mathrm{sa}\right)$

\begin{tabular}{cc}
\hline $\mathbf{C}_{\mathbf{p o}}(\mathbf{m g} / \mathbf{L})$ & \% Tüketim \\
\hline 1.0 & 97.5 \\
2.5 & 76.4 \\
5.0 & 63.2 \\
10.0 & 55.4 \\
\hline
\end{tabular}

\subsection{Dolgulu Kolon Reaktörde Görünür Tepkime Hoz Sabitinin Hesaplanmast}

Dolgulu kolon için 1. derece biyodegradasyon kabulü ile süreklilik denkliğinin çözümünden elde edilen Denklem 10 kullanılarak çeşitli akış hızları için görünür tepkime hız sabitleri hesaplanmış ve Tablo 3.'te çeşitli akış hızları için bulunan görünür tepkime hız sabiti değerleri sunulmuştur. Sıv1 akımındaki türbülansın artması, sıvı film difüzyon direncinin sebep olduğu kütle aktarım kısıtlamalarını düşürür, dolayısı ile tepkime hızı artar. Kolon Reynolds sayısinin artmasiyla deneysel $\mathrm{K}_{\mathrm{p}}$ değerlerinin artması teori ile uyum içindedir.

Tablo 3. Çeşitli akış hızlarında elde edilen görünür tepkime hız sabiti değerleri $\left(\mathrm{pH}=7, \mathrm{~T}=30^{\circ} \mathrm{C}, \mathrm{C}_{\mathrm{P}_{0}}=\right.$ $1 \mathrm{mg} / \mathrm{L}, \mathrm{w}=10.15 \mathrm{~g}, \boldsymbol{\varepsilon}=0.33$ )

\begin{tabular}{lcc}
\hline $\mathbf{Q},(\mathbf{m L} /$ dak.) & $\mathbf{C}_{\mathbf{C}} \mathbf{C}_{\mathbf{o}}$ & $\begin{array}{c}\mathbf{K}_{\mathbf{p}},\left(\mathbf{c m}^{\mathbf{3}} / \mathbf{g} \mathbf{~ k . ~ m o . ~}\right. \\
\mathbf{s a})\end{array}$ \\
\hline & & \\
1.17 & 100 & 31.85 \\
1.67 & 40 & 36.4 \\
2.16 & 30.30 & 43.5 \\
3.5 & 22.72 & 64.6 \\
4.0 & 19.6 & 70.35 \\
& & \\
\hline
\end{tabular}

\section{Tartışma ve Sonuçlar}

$\mathrm{Bu}$ çalışmada organofosforlu pestisitlerden phosmetin giderimi, $P$. fluorescens bakterisi ile dolgulu kolon reaktörde incelenmiştir. Elde edilen veriler besleme akış hızının etkisi ve phosmet derişiminin etkisi açısından değerlendirilmiştir. Çalışma kapsamında elde edilen genel sonuçlar aşağıda sunulmuştur.

Biyodegradasyon ortam bileşiminin pestisitlerin tüketimini büyük ölçüde etkilediği anlaşılmış ve ortamda başka bir karbon kaynağ 1 bulunduğunda bakterinin pestisiti tüketmek yerine kullanımı daha kolay olan diğer karbon kaynağını tercih ettiği anlaşılmıştır. Mikroorganizmalar ortamda bulunan pestisitleri karbon kaynağ 1 olarak tüketmekte ve böylece çok önemli bir çevre kirleticisi olan pestisitleri ortamdan uzaklaştırmaktadırlar. $\mathrm{dp}=2$ $\mathrm{mm}$ çaplı tutuklanmış $P$. fluorescences tanecikleri ile dolgulu kolon reaktörde, öncelikle $1 \mathrm{mg} / \mathrm{L}$ phosmet derişiminde besleme akış hızının phosmet tüketim hızına etkisi incelenmiştir. Akış hızı arttıkça film difüzyon direncinin azaldığ 1 ve phosmet tüketim hızının arttı̆̆ gözlenmiştir. En yüksek phosmet \% tüketim değeri (\% 99) en düşük akış hızında (1.17 mL/dak) elde edilmiştir. Amaç yüksek dönüşüm yüzdesi elde etmek olduğu kadar, yüksek phosmet tüketim hızını da sağlamak olduğundan $1.67 \mathrm{~mL} / \mathrm{dak}$ akış hızı daha sonraki denemelerde kullanılabilecek akış hızı olarak belirlenmiştir. Bu akış hızında elde edilen phosmet tüketim hızı; $0.0096 \mathrm{mg} / \mathrm{g}$ k.mo.sa, tüketim yüzdesi ise \% 97.5 'dur. Dolgulu kolon reaktörde phosmet giderimi \% 99 olarak belirlenmiştir. Yahiat vd., (2011) yaptıkları çalışmalarında, Pseudomonas fluorescens kullanarak siprokonazol fungusitinin sudaki giderimini hibrit fotokataliz ve biyolojik arıtma prosesiyle araştırmışlardır. Çalışmada 500 dakika aydınlatma sonunda, $85 \mathrm{mg} / \mathrm{L}$ siprokonazol giderimi yapılmıştır. Sonraki biyolojik arıtma için artık organik madde miktarı önemli olduğundan, $\% 85,8$ parçalanma, $\% 38,5$ mineralizasyon ve $\% 51,6$ oksidasyonun olduğu 255 dakikalık aydınlatma süresi seçilmiştir. Sonuçta, sulardan siprokonazol gideriminde biyolojik arıtım öncesi fotokataliz prosesi başarılı olmamıştır. Oysa bizim çalışmamızda $P$. fluorescens kullanarak dolgulu kolon reaktörde $10 \mathrm{mg} / \mathrm{L}$ phosmet derişiminde \%55.4 giderim sağlanmıştır.

Tutuklanmış mikroorganizma sistemlerinin kullanımı ile yoğun hücre derişimi sağlanır ve mikroorganizmalar uzun süre biyolojik aktivitelerini kaybetmeden kullanılabilirler. Ayrıca $\mathrm{pH}$, sıcaklık, substrat derişimi gibi ortam özelliklerinden daha az etkilendiklerinden daha 
geniş $\mathrm{pH}$, sıcaklık, substrat derişim aralıklarında kullanılabilirler.

Dolgulu kolon reaktörde mikroorganizma miktarı ve akış hızı ayarlanarak istenilen phosmet tüketim hızı ve dönüşüm değerlerinde çalışmak mümkündür. Tek geçişte yüksek dönüşüm istendiğinde düşük akış hızlarında çalışmak gerekir. Yüksek akış hızlarında dönüşüm azalır. Geri döngü yapılarak verim artırılabilir. Sistem substrat inhibisyonundan daha az etkilendiğinden yüksek phosmet derişimlerinde çalışılabilir. Arıtılmış atıksuyun mikroorganizmalardan kolayca ayrılabilmesi sistemin önemli bir üstünlüğüdür. Besleme çözeltisi sürekli akış halinde olduğundan diğer mikroorganizmalar uygun üreme ortam1 bulamazlar. Dolayısıyla sistemde bulaşma gözlenmez. Arıtılacak atıksu miktarı fazla, phosmet derişimi yüksek ise dolgulu kolon reaktör sistemi akış hızı ve mikroorganizma miktarı ayarlanarak başarı ile uygulanabilir.

\section{Teşekkür}

Bu Makale Selin Y1lmaz Durdu'nun Yüksek Lisans Tezi'nden üretilmiştir. Makalenin inceleme ve değerlendirme aşamasında yapmış oldukları katkılardan dolayı editör ve hakem/hakemlere de teşekkür ederiz.

\section{Kaynaklar}

Antonious, G.F., 2012. On-farm Bioremediation of Dimethazone and tTrifluralin Residues in Runoff Water from an Agricultural Field. Journal of Environmental Science and Health, 47(7), 608621.

Ardıç, G., 2013. Yukarı Sakarya Havzası'nda Yaşayan Balık Türlerindeki Organoklorlu Pestisit Kalıntılarının Mevsimsel Olarak Belirlenmesi. Doktora Tezi, Afyon Kocatepe Üniversitesi, Afyonkarahisar, Türkiye,

Bending, G.D., Lincoln, S.D., Sorensen, S.R., Morgan, J.A.W., Aamand, J. ve Walker, A., 2003. In-field Spatial Variability in the Degradation of the Phenyl-urea Herbicide Isoproturon is the Result of Interaction Between Degradative Sphingomonas spp. and Soil pH. Applied Environmental Microbiology, 69, 827-834.

Chen, Y, Wen, X., Wang, B. ve Nie, P., 2017. Agricultural Pollution and Regulation: How to Subsidize Agriculture?. Journal of Cleaner Production, 164, 258-264.

Chowdhury, A., Pradhan, S., Saha, M. ve Sanyal, N., 2008. Impact of Pesticides on Soil Microbiological Parameters and Possible Bioremediation Strategies. Indian Journal Microbiology, 48, 114
Copley, S.D., 2009. Evolution of Efficient Pathways for Degradation of Anthropogenic Chemicals. Nature Chemical Biology, 5(8):559-66.

Curutiu, C., Lazar, V. ve Chifiriuc, M.C., 2017. Pesticides and Antimicrobial Resistance: from Environmental Compartments to Animal and Human Infections. New Pesticides and Soil Sensors, Academic Press, 373-392.

Feakin, S.J., Gubbins, B., McGhee, I., Shaw, L.J. ve Burns, R.G., 1995. Inoculation of Granular Activated Carbon with S-Triazine Triazinedegrading Bacteria for Water Treatment at Pilot-Scale. Water Research, 29 (7), 16811688.

Fernandez-Alba, A.R., Hernando, D., Agüera, A., Caceres, J. ve Malato, S., 2002. Toxicity Assays: a Way for Evaluating AOPs Efficiency. Water Research, 36 (17), 4255-4262.

Hillocks, R.J., 2012. Farming with Fewer Pesticides: EU Pesticide Review and Resulting Challenges for UK Agriculture. Crop Protection, 31(1), 85-93.

Jasim, S.Y., Irabelli, A., Yang, P., Ahmed, S. ve Schweitzer, L., 2006. Presence of Pharmaceuticals and Pesticides in Detroit River Water and the Effect of Ozone on Removal. Ozone: Science \& Engineering, 28(6), 415-423.

Kitiş, M., 2014. Sularda Tehlikeli ve Öncelikli Maddeler-Arıtma Prosesleri, OSİB, Su Yönetimi Genel Müdürlüğü, Personel Eğitimi, 5 Kasım, Afyon.

Pazı, İ., Gönül, L.T. ve Küçüksezgin, F., 2013. Pesticide and PCB Residues in Biotic and Abiotic Environment in Lake Bafa. Ege Journal of Fisheries and Aquatic Sciences, 30(4), 175-182.

Radosevich, M., Traina, S.J., Hao, Y.L. ve Touvinen, O.H., 1995. Degradation and Mineralization of Atrazine by a Soil Bacterial Isolate. Applied Environmental Microbiology, 61, 297-302.

Storck, V., Karpouzas, D.G. ve Martin-Laurent, F., 2017. Towards a Better Pesticide Policy for the European Union. Science of Total Environment, 575, 1027-1033.

Struthers, J.K., Jayachandran, K. ve Moorman, T.B., 1998. Biodegradation of Atrazine by Agrobacterium Radiobacter J14 a and use of this Strain in Bioremediation of Contaminated Soil. Applied Environmental Microbiology, 64, 33683375.

Yahiat, S., Fourcade, F., Brosillon, S. ve Amrane, A., 2011. Photocatalysis as a Pre-treatment Prior to a Biological Degradation of Cyproconazole. Desalination, 281, 61-67.

Yilmaz, S., 2012. Organofosforlu Pestisitlerden Phosmetin Pseudomonas fluorescens ile Biyodegradasyonunun Kesikli ve Sürekli Sistemlerde Araştırılması. Fırat Üniversitesi Fen Bilimleri Enstitüsü Yüksek Lisans Tezi. 